\title{
Preservation of Washed Spermatozoa of Mehsana Buck at Refrigeration Temperature
}

\author{
V R Parmar, B N Suthar, V K Sharma, H C Nakhashi* and S S Parikh \\ Department of Gynaecology and Obstetrics \\ College of Veterinary Science and Animal Husbandry \\ Clinical Complex Deesa, S.D. Agricultural University, Sardar Krushinagar - 385 506, India \\ * Corresponding author email: hcnakhashi@yahoo.co.in \\ Received: 16-10-2011, Accepted: 27-11-2011, Published Online: 26-01-2012 \\ doi: 10.5455/vetworld.2012.294-296
}

\begin{abstract}
The study was done to understand the preservation of Washed Spermatozoa of Mehsana Buck at Refrigeration temperature. The washed spermatozoa from 78 semen ejaculates, 26 each from 3 Mehsana bucks, were preserved at $4 \pm 1^{\circ} \mathrm{C}$ temperature in SM and TCFEY diluents up to 72 hours and the physical characteristics of spermatozoa were studied to assess the suitability of diluents. The individual sperm motility and live spermatozoa decreased significantly whereas abnormal spermatozoa increased significantly $(\mathrm{P}<0.05)$ at each $12 \mathrm{hrs}$ interval of preservation in two diluents. The effect of diluents on spermatozoan characteristics was less pronounced in SM than TCFEY diluent. Among the interaction studies, stage of preservation affected the live spermatozoa and their morphology. The findings suggested superiority of SM diluent over TCFEY for preservation of Mehsana buck semen.
\end{abstract}

Key Words: Buck, Diluents, Ejeculates, Semen Preservation, Spermatozoa.

To cite this article :

Parmar VR, Suthar BN, Sharma VK, Nakhashi HC and S S Parikh (2012) Preservation of Washed Spermatozoa of Mehsana Buck at Refrigeration Temperature, Vet. World. 5(5):294-296, doi: 10.5455/vetworld.2012.294-296

\section{Introduction}

Artificial Insemination is a major concern in progeny testing programme of small animals which are generally reared in small geographical areas. The semen cooled to low or ultra low temperature has to be utilized for this purpose, however, the resultant fertility remains higher in Norwegian dairy goats by using semen stored at $4-5^{\circ} \mathrm{C}$ in comparison to frozen (Leboeuf et al. 2000 and Paulenz et al, 2005). These workers have reported the Skimmed milk and Tris-egg yolk diluents for preservation of buck semen. The beneficial effect of washing on viability of spermatozoa of crossbred bucks (Beetal x Assam local) and its storage ability up to $72 \mathrm{hrs}$ of preservation at refrigeration temperature has been reported by Islam et al. (2006) while; Ranjan et al. (2009) documented the similar benefits in Marwari buck semen extended in diluents containing $10 \%$ egg yolk. However, there does not seem any information on Mehsana Buck.

Therefore, the present investigation on preservation of Mehsana buck semen at refrigeration temperature vis-à-vis physical characteristics of spermatozoa was undertaken to evaluate the suitability of SM and TCFEY diluents.

\section{Materials and Methods}

The research protocol was conducted with a prior permission of Institutional Animal Ethics Committee, College of Veterinary Science, Sardarkrushinagar Dantiwada Agricultural University, Sardarkrushinagar. Three Mehsana bucks of breeding age, 12 to 18 months, were trained on teaser of same breed for two months to ejaculate the semen in Artificial Vagina; and there after utilized to obtain 26 semen ejaculates from each buck twice weekly during the period of three months.

A total of seventy eight ejaculates of acceptable quality were divided in two equal aliquots immediately after collection and each of them was washed to remove the coagulating enzyme using Krebs-RingerPhosphate-Glucose solution @ of 1: 9 followed by centrifugation at $3000 \mathrm{rpm}$ for 5 min (Chemineau et al., 1991). The supernatant was removed to obtain the sperm pack which was diluted in two different dilutors: Tris - Citric acid - Fructose - Egg yolk (TCFEY) and Skim Milk (SM) at the dilution ratio of 1:10 (Deka and Rao, 1986, Corteel, 1974). The samples were preserved at $5^{\circ} \mathrm{C}$ temperature and were evaluated after $12,24,36$, 48, 60 and $72 \mathrm{hrs}$ of preservation. The data were 
Preservation of Washed Spermatozoa of Mehsana Buck at Refrigeration Temperature

Table-1: Spermatozoan characteristics during refrigeration preservation of buck semen in TCFEY and SM diluents.

\begin{tabular}{|c|c|c|c|c|c|c|}
\hline Dilutor/Stage & $12 \mathrm{~h}$ & $24 \mathrm{~h}$ & $36 \mathrm{~h}$ & $48 \mathrm{~h}$ & $60 \mathrm{~h}$ & $72 \mathrm{~h}$ \\
\hline \multicolumn{7}{|l|}{ Individual sperm motility } \\
\hline TCFEY & $80.82+0.34^{\mathrm{fa}}$ & $75.58+0.31^{\mathrm{ea}}$ & $70.26+0.36^{d a}$ & $64.75+0.27^{\mathrm{ca}}$ & $59.01+0.24^{\text {ba }}$ & $52.55+0.46^{\mathrm{aa}}$ \\
\hline TCFEY & $83.60+0.15^{\dagger}$ & $78.92+0.23^{\mathrm{ea}}$ & $73.87+0.22^{\mathrm{da}}$ & $68.57+0.24^{\mathrm{ca}}$ & $62.44+0.30^{\text {ba }}$ & $55.19+0.44^{\mathrm{az}}$ \\
\hline $\begin{array}{l}\text { SM } \\
\text { Abnormal sperm count }\end{array}$ & $84.19+0.13^{f}$ & $80.02+0.22^{\mathrm{eb}}$ & $75.32+0.35^{\mathrm{db}}$ & $70.61+0.24^{\mathrm{cb}}$ & $65.23+0.46^{b b}$ & $59.32+0.52^{\mathrm{ab}}$ \\
\hline SM & $6.43+0.79^{\mathrm{aa}}$ & $7.96+0.76^{\mathrm{ba}}$ & $9.98+0.82^{\mathrm{ca}}$ & $12.18+0.78^{\mathrm{da}}$ & $15.05+0.66^{\mathrm{ea}}$ & $18.38+0.63^{\mathrm{fa}}$ \\
\hline
\end{tabular}

Means bearing different superscripts in columns and subscripts in rows differ significantly $(p<0.05)$.

Table-2: Analysis of variance for spermatozoan characteristics in TCEFY and SM diluents during refrigeration preservation in Mehsana bucks.

\begin{tabular}{llccc}
\hline Source & d.f. & Individual motility count (M.S.) & Live sperm count count (M.S.) & Abnormal sperm Count (M.S.) \\
\hline Buck & 2 & $124.181^{*}$ & $31.792^{\mathrm{NS}}$ & $434.056^{*}$ \\
Dilutor & 1 & $379.504^{*}$ & $910.181^{*}$ & $1352.163^{*}$ \\
Stage & 5 & $16800.907^{*}$ & $15202.515^{*}$ & $4094.163^{*}$ \\
Buck $\times$ Dilutor interaction & 2 & $2.315^{\mathrm{NS}}$ & $12.524^{\mathrm{NS}}$ & $3.282^{\mathrm{NS}}$ \\
Buck $\times$ Stage interaction & 10 & $1.868^{\mathrm{NS}}$ & $6.743^{\mathrm{NS}}$ & $1.429^{\mathrm{NS}}$ \\
Dilutor $\times$ Stage interaction & 5 & $5.599^{\mathrm{NS}}$ & $79.416^{*}$ & $65.058^{*}$ \\
Buck $\times$ Dilutor $\times$ Stage interaction & 10 & $2.520^{\mathrm{NS}}$ & $4.290^{\mathrm{NS}}$ & $0.619^{\mathrm{NS}}$ \\
Error & 900 & $36.71^{\mathrm{NS}}$ & 24.29 & 6.69 \\
\hline
\end{tabular}

* Significant at $5 \%$ level NS = Non-significant

analyzed by factorial CRD having 3 factors (Snedecor and Cochran, 1980).

\section{Results and Discussion}

The data pertained to individual sperm motility, live spermatozoa and their abnormalities at different hours of preservation in TCFEY and SM diluents are presented in Table 1. The findings showed significant decrease in individual sperm motility and live spermatozoa at all stages of preservation in both diluents. These two traits of spermatozoa were observed to curtail more than 25 percent at 72 hrs of preservation in comparison to their initial values. Other workers have also reported a considerable decline in live spermatozoa and initial sperm motility in TCFEY and SM diluents (Das et al.., 1985, Mishra et al.1993, Takerkhede et al. 2005). On the other hand, the morphological abnormalities of spermatozoa increased linearly and reached beyond the acceptable limit at $72 \mathrm{hrs}$ of preservation to both diluents. Simon et al. (2003) also documented an increased percentage of sperm abnormalities as the duration of preservation advanced.

The effect of diluents and bucks were variable on spermatozoon characteristics. The individual sperm motility, live spermatozoa and morphological abnormalities differed significantly due to these two variances whereas live spermatozoa remained unaffected among the bucks (Table-2). Almost similar findings have been reported by earlier works in bucks (Mishra et al., 1993; Puranik et al., 1994) and Patanwadi rams (Kakdiya, 1993).

The comparative findings of two dilutors revealed the significant differences in all three spermatozoon characteristics (Table-1). The superiority of SM diluent over the TCFEY diluent was reflected at all stages of preservation in our study (Table-1), which corroborates with the earlier findings in Osmanbadi and crossbred buck semen as reported by John and Raja (1973); Das et al.(1985) and Puranik et al. (1994). However, the findings of Singh et al. (1980) suggested higher sperm motility in buck semen using egg yolk citrate. This variation might be attributed to the breed characters of buck used in different studies besides the holding time of washed spermatozoa as suggested by Islam et al. (2006).

The sperm abnormalities were found to be less in SM diluent than the TCFEY at each stage of preservation. The differences were progressive with a range of 1-4 percent during the entire period of semen 
preservation in our study. The increase in these abnormalities mounted to $22.41 \pm 0.57$ and $18.38 \pm$ 0.63 percent in TCFEY and SM diluents, respectively at $72 \mathrm{hrs}$ of preservation. In earlier study, 11.5 percent abnormalities using tris diluent at $96 \mathrm{hrs}$ of refrigeration has been reported by Takakhede et al. (2005).

The interaction of diluents and stages of preservation was found to be significant only for the live and abnormal spermatozoa whereas other interactions with regards to buck x diluents, buck x stages of preservation were non-significant on spermatozoa characteristic. Kakadiya (1993) also reported significant interaction of stage $\mathrm{x}$ dilutors on initial motility, live percent and abnormality of spermatozoa in Patanwadi rams.

\section{Acknowledgements}

The authors are thankful to the Authority of Sardarkrushingar Dantiwada Agricultural University for providing various facilities to conduct the Research work in the Department of Gynaecology and Obstetrics, College of Veterinary science and A.H. and at Livestock Research Station, Sardarkrushinagar

\section{Conflict of interest}

Author declare that they have no conflict of interest.

\section{References}

1. Chemineau, P., Varo, H., and Grude, A. (1986). Sexual behaviour and gonadal activity during the year in the tropical Creole meat goat. II. Male mating behaviour, testis diameter, ejaculate characteristics and fertility. Reprod. Nutr. Develop, 26(2A): 453-460.

2. Corteel, J. M. (1974). Viabilite des spermatozoids de bouc conserves avec ou sans leur plasma seminal: Effet du glucose. Ann. Biol. Anim. Biochim. Biophys., 14: 741-745.

3. Das, A., Kakati, B. N., Rajkonwar, C. K. and Borgohain, B. N. (1985). Survival of buck spermatozoa in egg yolk citrate milk and tris diluent at $4^{\circ}$ C. Indian J. Anim. Sci., 55(8): 670-672.

4. Deka, B. C. and Rao, A. R. (1986). Motility of buck spermatozoa during preservation at $5^{\circ} \mathrm{C}$ with and without seminal plasma. Indian Vet. J., 63(2): 169-170.
5. Islam, R., Ahmed, K. and Deka, B.C. (2006). Effect of holding and washing on the quality of goat semen. Small Ruminant Research, 66(1-3):51-57.

6. John, K. L. and Raja, C. K. S. V. (1973). A study on preservation of buck semen. Kerala J. Vet. Sci., 4: 90.

7. Kakadiya, P. T. (1993). Comparative efficacy of different dilutors for preservation of Patanwadi ram semen at refrigeration. M.V.Sc. thesis submitted to Gujarat Agricultural University, Sardarkrushinagar, Gujarat, India.

8. Leboeuf, B., Restall, B. and Salamon, S., (2000). Production and storage of goat semen for artificial insemination. Anim. Reprod. Sci., 62: 113-141.

9. Misra, D. N., Deka, B. C. and Borgohain, B.N. (1993). Effect of egg yolk level in tris extender on preservation of goat semen at $5^{\circ} \mathrm{C}$. Indian Vet. Med.J., 17: 76-78.

10. Paulenz, H., Soderquist, L., Adnoy, T., Soltun, K., Saether, P.A. and Fjellsoy, K.R. (2005). Effect of cervical and vaginal insemination with liquid semen stored at room temperature on fertility of goats. Anim. Reprod. Sci., 86: 109-117.

11. Puranik, S. V., Pargaonkar, D. R., Bakshi, S. A. and Markandeya, N. M. (1994). Preservation of Osmanabadi and Crossbred buck semen at refrigeration temperature. Indian J. Anim. Reprod., 15(1): 57-59.

12. Ranjan, R., Ramchandran,N., Jindal, S.K., Goel, A.K. and Kharche, S.D.(2009).Effect of egg yolk levels on keeping quality of Marwari buck semen at refrigeration temperature. Ind. J. Anim. Sci. 79 (7): 662-664.

13. Simon, L. and Vijayakumaran, V. (2003). Effect of preservation at refrigeration temperature on bacterial load and quality of buck semen. Indian J. Anim. Reprod., 24(1): 71-72.

14. Singh, M. P., Sinha, S. N. and Singh, B. (1980).... Proc. $2^{\text {nd }}$ All India Symp. Anim. Reprod., University of Agricultural Sciences, Hebbal, Bangalore. (c.f. Borgohain et al., 1985).

15. Snedecor, G. W. and Cochran, W. G. (1980). Statistical methods. Seventh Edn. Oxford and IBH Publication Co., Calcutta.

16. Takarkhede, R. C., Bane, K. B., Kuralkar, S. V., Kolte, A. Y. and Sahatpure, S. K. (2005). Effect of storage at refrigerator temperature on buck semen diluted in tris egg yolk citrate diluent. Indian Vet. J., 82(5): 564.

$$
* * * * * * * *
$$

